\title{
Syringocystadenoma papilliferum presented as an ulcerated nodule of the vulva in a patient with Neurofibromatosis type 1
}

\author{
lyda El Faqyr', Maria Dref², Sara Zahid', Jamila Oualla', Nabil Mansouri², Hanane Rais², \\ Ouafa Hocar', Said Amal' ${ }^{1}$
}

${ }^{1}$ Department of Dermatology, Mohammed VI University Hospital, University Cadi Ayyad, Marrakech, Morocco, ${ }^{2}$ Department of Pathology, Mohammed VI University Hospital, University Cadi Ayyad, Marrakech, Morocco

Corresponding author: Dr. Iyda El Faqyr, E-mail: iydaelfaqyr@gmail.com

\begin{abstract}
A 36-year-old female presented to the dermatology service with a pinkish to erythematous ulcerated nodule measuring about $1 \mathrm{~cm}$ in diameter, located on the labia majora. The lesion has been slowly increasing in size. Physical examination found features compatible with the diagnosis of neurofibromatosis type 1. Excisional biopsy demonstrated the histological picture of syringocystadenoma papilliferum. The interest of this report lies in the rarity of syringocystadenoma papilliferum, its unusual presentation in the vulva, and it's association with neurofibromatosis type 1 . To our knowledge, this association has not been described in the medical literature.
\end{abstract}

Key words: Syringocystadenoma papilliferum; Neurofibromatosis type 1; Vulva

\section{INTRODUCTION}

Syringocystadenoma papilliferum (SCAP) is an uncommon benign adnexal tumor, which frequently arises from a nevus sebaceous. This tumor occurs usually at birth or during early childhood. It's most commonly located on the scalp or face, however SCAP in other areas have been reported [1]. Location in the vulva is rare and had only been reported in very few cases[2]. Neurofibromatosis typel (NF1) is a frequent neurocutaneous syndrome that predisposes for various benign and malignant tumors. We report a case of SCAP located in the vulva in a NFl patient.

\section{CASE REPORT}

We report the case of a 36 years old patient, treated one year ago for a breast carcinoma in situ. With a family history of neurofibromatosis type 1 in the father, the dead brother and the sister. Physical examination showed many flat, uniformly hyperpigmented macules with well-defined borders over the body, corresponding to café-au-lait macules (Fig. 1). Skinfold freckling were present all over the trunk (Fig. 1). Examination of the genital area objectified a pinkish to erythematous bordered elevated ulcerated nodule measuring about $1 \mathrm{~cm}$ in diameter, unpainful, located in the inside of the labia majora (Fig. 2). There were no other genital or perineal lesions. Ophthalmological examination found several bilateral Lisch nodules. The patient meted National Institutes of Health criteria for NF14 (4/7 criteria). Other physical examination showed dosrsolumbar scoliosis. The vulvar lesion was fully excised, histopathology revealed a tumor with endophytic configuration, composed of papillary projections and ductal-like structures that extend as invaginations from the surface epithelium into the underlying dermis. The papillary projections covered by regular cubic epithelium. The ducts and papillary projections are covered by an inner layer of columnar epithelium and an outer layer of cuboidal or flattened

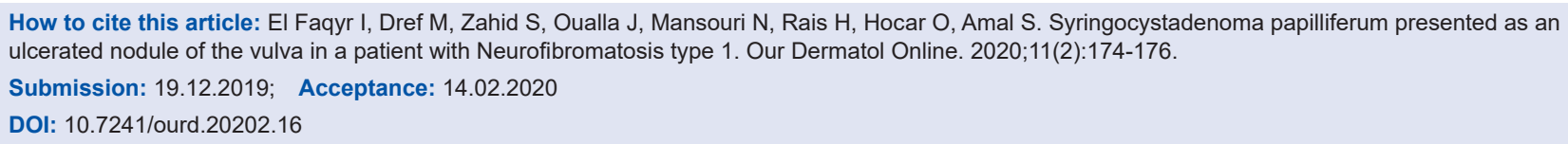




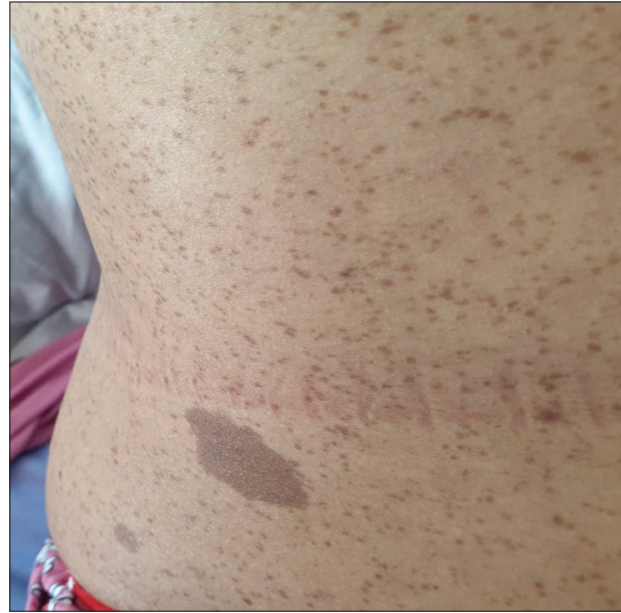

Figure 1: Café-au-lait macule with multiple freckling on the trunk.

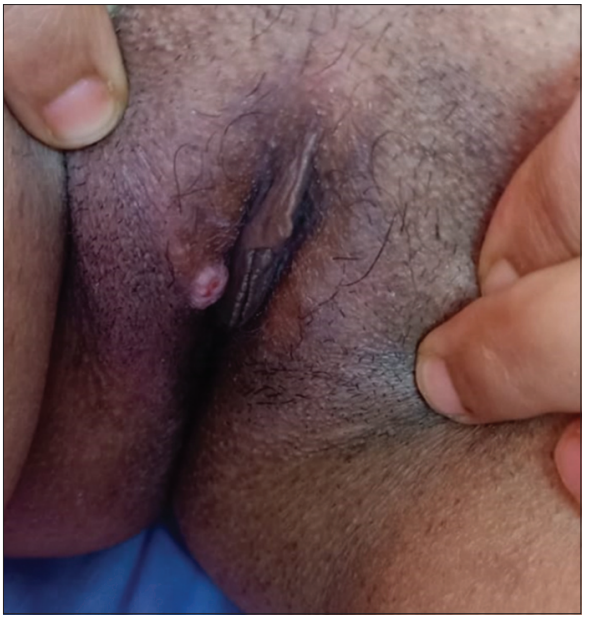

Figure 2: Pinkish to erythematous bordered elevated ulcerated nodule measuring $1 \mathrm{~cm}$ in diameter on the labia majora.

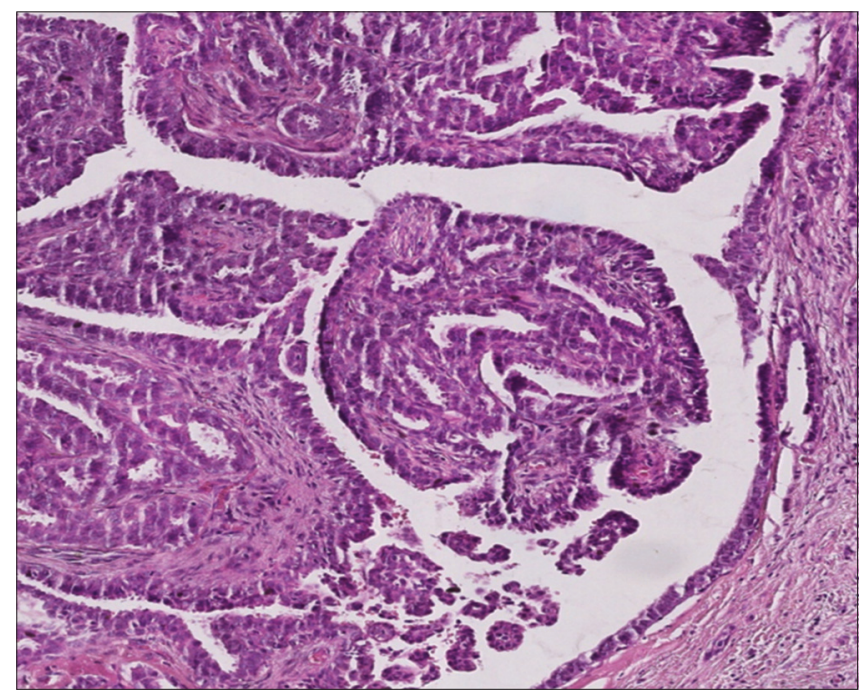

Figure 3: Histological section $(\mathrm{H}$ and $\mathrm{E} \times 20$ ) showing papillary epithelial proliferation lined with a double layer of cuboidal and cylindrical cells.

cells confirming the diagnosis of SCAP (Fig. 3). There were no features of associated sebaceous hamartoma, nuclear atypia or any signs of malignancy. No recurrence was noted with four months follow-up.

\section{DISCUSSION}

Syringocystadenoma papilliferum is presumably derived from pluripotent cells and differentiates toward eccrine and/or apocrine apparatuses [3]. There is also a possibility that SCAP can resemble lesions of the breasts deriving from the supernumerary mammary tissues from milk ridges. In some individuals those ridges may not regress completely during embryological development forming breast-like tissue [2]. The most frequent location is the head and neck. Less frequently involved sites are face, chest, abdomen, arm, thighs, and perineum, location on vulva had only reported in few cases. The clinical presentation varies widely, making the clinical diagnosis of SCAP quite difficult. The tumor can present as a solitary nodule or greyish-brown papule with smooth and flat dome. Large nodules can ulcerate. Main dermoscopic features are exophytic papillary structures and polymorphous vesselsl. Histopathologic appearance is uniform and characteristic the basis of diagnosis [3]. It typically shows varying degrees of papillomatosis along with cystic invaginations and malformed sebaceous glands. Immunohistochemistry helps in differentiating the origin of the tumor, either eccrine or apocrine, positive immunoreactivity for proteins 15 and 24 and zinc-2 glycoprotein demonstrates evidence of apocrine differentiation, while positivity for CKs demonstrates eccrine differentiation [4]. Mari Kishibe and al [5] described a case of SCAP with a unique histopathology. The tumor was composed of basaloid cell proliferation interconnecting from the epidermis to the dermis. Ductal structures in the tumor were lined by club-shaped columnar cells with apical snouts. Numerous vacuolated cells with hyaline globulelike cytoplasmic inclusions were present among the columnar cells, the content of which was identified as sialomucin. Syringocystadenoma papilliferum is frequently seen in association with other benign adnexal lesions such as apocrine naevi, tubular apocrine adenomas, apocrine hidrocystomas, trichoadenomas, apocrine cystadenomas and clear cell syringomas [1]. Treatment of SCP is based on surgical excision, which is recommended for ulcerated forms or large size. When the location is unfavorable for surgical treatment, the CO2 laser therapy represents a good alternative [6]. Neurofibromatosis type 1 is one of the most frequent hereditary neurocutaneous disorders with a birth 
incidence of about $1 / 2500$. It is caused by heterozygous germ-line mutations in the tumor suppressor gene NF1 which codes for neurofibromin, a negative regulator of the RAS proto-oncogene [7]. This makes NF1 patients at risk to develop various benign and malignant tumors. Authors [7] revealed that the range of NFl associated tumors extends beyond nervous system and includes cancers of the lung, thyroid gland, skin, ovary and gastrointestinal tract. Our patient with the history of removed breast cancer, developed SCAP. To our knowledge, the association between NFl and SCAP has not been described yet in the medical literature. Although this tumor had relatively benign course, rare cases of malignant transformation have been reported.

\section{CONCLUSION}

This case report contributes to extending NFl associated tumors, and reconsider differential diagnoses of a chronic ulcerated lesion in the vulva. Our patient requires continuous and permanent monitoring to detect other neoplasms.

\section{Consent}

The examination of the patient was conducted according to the Declaration of Helsinki principles.

The authors certify that they have obtained all appropriate patient consent forms. In the form the patient(s) has/have given his/her/their consent for his/ her/their images and other clinical information to be reported in the journal. The patients understand that their names and initials will not be published and due efforts will be made to conceal their identity, but anonymity cannot be guaranteed.

\section{REFERENCES}

1. Mara L, Simonetta P, Caterina L, Borsari S, Persechino F, Argenziano $G$, et al. Dermoscopy of syringocystadenoma papilliferum. Austral J Dermatol. 2017;59:e59-e61.

2. Oleksandr S, Nirmala C, Frank L. Syringocysadenoma papilliferum of the vulva: a rarity in gynaecology. BMJ Case Rep. 2014;2014. pii: bcr2014203902.

3. Mohamed M, Belhadjali M, Hadhri R, Youssef M, Zili J. Clinical aspects of syringocystadenoma papilliferum. Our Dermatol Online. 2017;8:348.

4. Shah PA, Singh VS, Bhalekar S, Sudhamani S, Paramjit E. Syringocystadenoma papilliferum: A rare case report with review of literature. J Sci Soc. 2016;43:96-8.

5. Mari K, Takeshi I, Ichiro T, Akemi IY. Intracytoplasmic eosinophilic inclusion bodies with embryonic folliculosebaceous-apocrine unit differentiation in syringocystadenoma papilliferum. J Cutan Pathol. 2018;45:923-6.

6. Bettioui A, Bouyahyaoui Y, Gallouj S. Syringocystadénome papillifère congénital. Ann Dermatol Vénéréol. 2012;139:647-51.

7. Rosenbaum T, Wimmer K. Neurofibromatosis type 1 (NF1) and Associated tumors. Klin Padiatr. 2014;226:309-15.

Copyright by lyda El Faqyr, et al. This is an open access article distributed under the terms of the Creative Commons Attribution License, which permits unrestricted use, distribution, and reproduction in any medium, provided the original author and source are credited.

Source of Support: Nil, Conflict of Interest: None declared. 